fatigue 1 ; and syncope 1), and placebo-treated patient (1.6\%) withdrew because of nausea. Eighty percent of atomoxetine-treated patients completed the study, compared to $73 \%$ of those receiving placebo. (Kelsey DK, Sumner CR, Casat CD, et al. Once-daily atomoxetine treatment for children with attention-deficit/hyperactivity disorder, including an assessment of evening and morning behavior: a double-blind, placebo-controlled trial. Pediatrics July 2004;114:e1-e8). (Reprints: Douglas K Kelsey MD, PhD, Lilly Technology Center South, DC4135, Indianapolis, IN 46285).

COMMENT. This is the third study showing superior efficacy of once-daily atomoxetine $\left(\right.$ Strattera $^{\mathrm{R}}$ ) versus placebo in children with ADHD. Compared to previous studies (Heiligenstein et al. 2000; Michelson et al. 2001, 2002; and Newcorn 2002), this report extends the demonstration of efficacy, persisting not only into the evening but also the next morning, after a single morning dose. Contrary to some reports warning of a delayed onset of benefit with atomoxetine compared to methylphenidate, an effect is also measured on the first day of treatment. This study does not address school behavior, but teacher-rating scales completed in previous trials have shown significant benefits. Short-term studies point to some initial adverse events (decreased appetite, abdominal pain. drowsiness, and fatigue), but none life threatening and few resulting in discontinuance of therapy. In one long-term study (Wernicke et al, 2002), adverse events, including slight increases in blood pressure and heart rate, declined in frequency with continued therapy. Since atomoxetine is not considered a stimulant, it may be recommended as first-line therapy for ADHD in patients who present with comorbid tics, seizure susceptibility, and/or sleep disorders. Patients who fail to respond or develop persistent adverse events with stimulant therapy (methylphenidate, amphetamines) may be considered for treatment with atomoxetine. Those who have the hyperactive/impulsive subtype or combined type of ADHD, with behaviors that persist in the evening and early morning hours, may benefit more from the extended efficacy of atomoxetine compared to shorter acting stimulants. Notwithstanding the encouraging early reports of efficacy and safety of atomoxetine, it is a relatively new addition to the ADHD treatment regimen. My personal preference is to rely initially on well-tried and proven remedies. (Millichap JG. Attention Deficit Hyperactivity and Learning Disorders. Chicago, PNB Publishers, 1998).

Alternative/complementary therapy for ADHD. Zinc sulfate suppiements ( $55 \mathrm{mg} / \mathbf{d}$ day $)$, as adjunctive therapy with methylphenidate (MPH $1 \mathrm{mg} / \mathrm{kg} /$ day) in a double-blind, placebocontrolled trial in 40 children with combined subtype of ADHD, provided significantly greater improvement than $\mathrm{MPH}$ /placebo treatment, in a study at Teheran University of Medical Sciences, Iran (Akhondzadeh S, et al. BMC Psychiatry 2004;4:9; biomedcentral.com/1471-244X/4/9). Zinc levels and further evaluation of zinc supplements for ADHD are indicated.

\title{
MOTOR INCOORDINATION IN ADHD
}

The relationship between motor performance, attention deficit, impulsiveness, and hyperactivity in 42 school-aged children with ADHD (36 males, 6 females; mean age 8 years 2 months; range 6-11 years) was studied at National Taiwan University, Taipei, Taiwan. 
Children with ADHD had significantly impaired performance in fine and gross motor skills, as measured by the Bruininks-Oseretsky Test of Motor Proficiency and compared to 42 ageand sex-matched children without ADHD. Attention, impulse control, and parent ratings of activity level were the best predictors of gross motor skills, while attention and impulse control were the best predictors of fine motor skills for children with ADHD. Different behavioral processes may be involved in fine and gross motor performances. (Tseng $\mathrm{MH}$, Henderson A, Chow SMK, Yao G. Relationship between motor proficiency, attention, impulse, and activity in children with ADHD. Dev Med Child Neurol 2004;46:381-388). (Respond: Mei Hui Tseng ScD, School of Occupational Therapy, College of Medicine, National Taiwan University, 7 Chung-shan South Rd, Taipei, Taiwan 100).

COMMENT. Children with ADHD-combined type perform poorly in tasks that measure motor performance, attention, impulse control, and activity level. Sustained attention and impulse control are important predictors of both fine and gross motor skills. In this study, hyperactivity is a predictor of gross motor incoordination but is not significantly correlated with fine motor skills. Measures of motor performance should be included in the diagnostic criteria for ADHD. Based on the frequency of subtle neurologic abnormalities in children with ADHD and impaired motor performance (eg. tandem gait dyspraxia, impaired alternating forearm movements, mirror movements), a primary motor deficit is a more likely explanation than motor incoordination secondary to impaired attention and lack of impulse (inhibitory) control. Subclinical epileptiform abnormalities in the EEG are more prevalent in children with ADHD, especially the hyperactive/impulsive subtype (Deonna et al, 2000; Becker et al, 2004).

\section{PRIAPISM ASSOCIATED WITH METHYLPHENIDATE ${ }^{\text {SR }}$ (CONCERTA) WITHDRAWAL}

A 15-year-old boy with attention deficit hyperactivity disorder, inattention subtype (ADHD), developed stuttering priapism (intermittent, prolonged, painful erections) after withdrawal of OROS methylphenidate $\left(\right.$ Concerta $\left.^{\mathrm{R}}\right) 36 \mathrm{mg} /$ day, and is reported from Inova Fairfax Hospital for Children, Falls Church, VA, and Children's National Medical Center, Washington, DC. Symptoms began after the dose was increased from $27 \mathrm{mg} /$ day to 36 $\mathrm{mg} /$ day, 6 days per week, with scheduled withdrawal on Sundays. Symptoms were exacerbated when a dose of $54 \mathrm{mg} /$ day was prescribed later. An estimated 5 to 10 painful erections occurred on the first Sunday after one week of treatment, and each lasted 10 to 15 minutes or sometimes longer. On the following weekdays, erections recurred early AM on the school bus but stopped suddenly within 1 hour after taking the morning dose, only to return the following morning. After reducing the dose to $27 \mathrm{mg} /$ day and gradually discontinuing treatment completely, symptoms immediately disappeared, with no recurrence of priapism at 6 months follow-up. Urinalysis for other drugs was negative. (Schwartz RH, Rushton HG. Stuttering priapism associated with withdrawal from sustained-release methylphenidate. J Pediatr 2004;144:675-676). (Reprints: Richard H Schwartz MD, 115 Park St SE, Ste 203, Vienna, VA 22180). 